\title{
Erratum to: Effects of Surface Properties of Organic Matters on Cation Adsorption in Solution Phase
}

\author{
Mingrui Yuan • Zhi Ping Xu • Thomas Baumgartl • \\ Longbin Huang
}

Published online: 25 September 2014

(C) Springer International Publishing Switzerland 2014

\section{Erratum to: Water Air Soil Pollut DOI 10.1007/s11270-014-2100-0}

The original publication of this article (DOI 10.1007/ s11270-014-2100-0) unfortunately contained an error.

The given name of the third author "Thomas" was incorrectly spelled as "Thamos". The correct names of all authors are provided here.

The online version of the original article can be found at http://dx.doi. org/10.1007/s11270-014-2100-0.

M. Yuan · T. Baumgartl $\cdot$ L. Huang Centre for Mined Land Rehabilitation, Sustainable Minerals Institute, The University of Queensland,

Brisbane, QLD 4072, Australia

Z. P. Xu $(\bowtie)$

Australian Institute for Bioengineering and Nanotechnology,

The University of Queensland,

Brisbane, QLD 4072, Australia

e-mail: z.xu1@uq.edu.au 